\title{
AS A UNIVERSAL EDUCATIONAL GOAL
}

\section{1. "Adulthood" as an educational goal}

In some educational circles the aim of pedagogy (the leading/guiding of children) is circumscribed or indicated as "adulthood", "which is commonly accepted as the first and the natural destination of the child who is on his journey through the world. Education ... is to lead/guide or to accompany a child on his way to the adulthood worthy of a human being as its aim" (Gunter, 1970, p. 9). In this respect one comes across several (vague) references in literature to "the idea of adulthood", the "norm figure of adulthood" being "the natural destination of every child", "the figure (form) of adulthood" (Landman \& Gous, 1969, p. 80), "the ideal figure of adulthood" (as opposed to a "phantom of adulthood"), "a norm figure which is worth striving for" (ibid, p. 81). The authors just referred to rightly come to the conclusion that "content should be given to the idea of adulthood" (Landman, Roos \& Liebenberg, 1971, p. 145).

Since it is a widely accepted procedure to refer to "adulthood" as the aim of education, it becomes necessary to define what is meant by "adulthood". This is especially true in view of the fact that Landman et al (1971, p. 145) state that "the idea of adulthood is a pluralistic and complicaten structure, since the specific content of adulthood will vary from one community to the other depending on how much the concept of life which is accepted in such communities differs". In this short treatise the following two questions will have to be answered: What is the nature and content of "adulthood" when it is successivelv regarded as a universal goal of all education, and as the specific goal of Christian education?

\section{Some doubts about "adulthood" as the universal goal of education}

Before one can fruitfully reflect on the question put in the previous paragraph, it is necessary to take off briefly at a tangent: the writers to whom reference was made in the previous paragraph time and time again concede (and rightly so) that "coming to adulthood can not take place in a single moment" (Landman \& Gous, 1969, p. 81) and conscquently they refer to "adulthood as something incompletable" (Landman et al, 1971, p. 146). 
By implication, then, it is asserted that "adulthood" is the aim of education and at the same time that this goal is unattainable. That such is indeed the case the educator who knows and accepts the Scriptures will immediately concede: the Bible teaches him that man and his works (including his educative work) are always contaminated by sin, and that perfection can never by attained in this dispensation.

The question which presents itself in view of these considerations is whether it makes any sense to tell the educator (parent, teacher) that "adulthood" is to be regarded as the general aim of education. This serious doubt about "adulthood" as a general educational aim is underscored by the fact that any effort to define or to circumscribe "adul thood" suffers from the same shortcomings as the term "adulthood" itself: should one circumscribe "adulthood" as "moral adulthood" (Claassen, n.d., p. 77 refers to some writers who take this point of view), one would wallow in the following morass: is a person to be regarded as an "adult" if and when he is able to act "morally" correctly, if and when his conscience is developed to such an extent that he is able to do the "correct thing?" What is "morally" correct, and what is the "correct thing to do" anyway?

Orie could proceed in this fashion to produce also other possible circumscriptions of "adulthood" (and probably find that the problems and pitfalls are even more numerous and more acute): if "adulthood" is to be interpreted as "coming of age", should twemty-one years of age be regarded as a borderline between childhood and adulthood? Is a twenty-one year old "morally grown-up", is his conscience developed to the "adult level" - and what does "adult level" mean anyway? Can "adulthood" possibly mean that a person is entitled to vote for his MP, that he is entitled to possess a driver's license, or that he has passed matric? "To be of age" in some cultures indicates that a person has passed through initiation school successfully. Should one, on the other hand, regard "adultness" as the "freedom" to be "responsible", one has to cope with other problems: when is a person genuinely free from his own instincts and passions, and when should he be regarded as somebody who is free to fulfil his calling?

Some writers have carried their doubts about "adulthood" to near absurd lengths. Gisela Trösch (1978) asks for instance: "Who is to be regarded as an adult? Is it the person who has suffered a long period of waiting and who is now capable of reproducing? Or should we say: an adult is a person who, according to the prescription on the label of a bottle of medicine, may take two tablets instead of one? May, can dare and should he more than a child may, can dare and should?"

In educational circles there will always be those persons who are of the 
opinion that education is an event or action which is terminated when the educand reaches "adulthood". Whatever happens to a person after having attained "adulthood" can in their opinion not be regarded as education. According to them the acts of influencing, of leading, of forming and so or: (irrespective of the vagueness of all these terms) that take place after an educand has reached adulthood are per definition not to be regarded as education. The argument which is usually offered in defence of this point of view is more or less the following: "Adulthood" is not altogether as vague and undefined as is frequently suggested. On the contrary, it is frequently possible to say at a glance that a particular person is an adult. This opinion is based on an estimate of the person's stage of physical development. Judgment about the various other aspects of such a person's "adultness" can, however, not be passed after a single glance, but it is usually possible to judge after a single interview whether a person is childish, childlike, or an adult - whichever may be the case. What precisely is meant by these "labels" is not clear at the outset: it is frequently necessary to live with a person for some time before one can take an educated guess at the nature and "content" of such a person's (let us say) childishness. Only then is one able to qualify one's initial estimate of the other person's stage of development: one labels him "childish" because of his immature reasoning or thinking ability, because of his immature use of language, because of his immature social relationships, or because he is not able to distinguish between right and wrong, and so on.

To sum up: it is reasonable to experience doubts about "adulthood" as the universal goal of education. No definition or circumscription of "adult hood" is sufficiently specific not to be susceptible to misunderstanding or to more than one interpretation. It is therefore doubtful whether the term "adulthood" is useful to the educator and the educationalist. It is quite difficult to tell a student who is being trained as a teacher to aim his work in school at rendering his pupils "adults", and then not being able to say in specific terms what is actually meant by "adulthood". Furthermore, the student may entertain quite another conception of "adulthood" than his professor.

But let us not summarily discard "adulthood" as goal of education. It may have some value and use as a working hypothesis, but then it is essential to try and say precisely what is meant by "adulthood". In order to be able to do this, we have to return for a moment to the term "education". 


\section{Education (agogy) as a lifelong event}

In contrast to the point of view that education is terminated when "adulthood" is attained, the opinion is held by the present writer that education is only terminated by death, that education is always to be regarded as agogy, that is leading or guidance. More specifically, it is to be regarded as "leading/guiding upwards" (in the service of that arché, principle, origin, god (in the case of the Christian the God of the Scriptures) who has claimed the heart of the educator; i.e. religious service, cf. paragraph 5). According to Schoeman (1975, p. 40) "it means that educations literally 'feeding upwards'" ".

The leading/guiding, the forming, the influencing which a person under goes after his attainment of so-called "adulthood" is therefore education. Leading/guiding and influencing of a person is part and parcel of the total event of education which is only terminated by such a person's decease. (It is this total event which is subdivided into four distinct phases, phases which cannot be clearly demarcated and which do not abruptly shift from one to the other).

All kinds of "leading"/"guidance" of individuals - irrespective of the "agogic phase" in which it takes place - are education. This point of view can be substantiated as follows: education is founded in the historic modality; human development begins in the historic modality. Education means the unfolding of those modalities to which the historic modality retrocipates, and at the same time means that the historic modality itself has to be opened up. This takes place when the historic modality points in anticipatory fashion to the supra-historical normative functions of man, and eventually the pistic function (belief) (Van Wyk, 1974, p. 33).

The historic function of the educand (the person who is being led in the agogic event) which has "the power of forming" as its core of meaning has to be opened up in its supra-historical modal coherences of which the ethic modality is most prominent. Since, however, man's ethical function is not his highest ability "cthical adulthood" can not in itself be regarded as the universal goal of education.

The destination of all education is the whole of the nornative actstructure of the educand of whom the pistic function is the most complicated function. This indicates that the pistic function is the commanding function of man's (i.e. the educand's) act-structure, and consequently also of his ethical function (his second most complicated lunction or ability). Although education is aimed at the opening up of the total act structure of the educand, and although it is in the last instance aimed at the opening up 
of man's (the educand's) pistic function as his most complicated potentiality, it is at the ethical function that education at home is aimed in the first instance (Van Wyk, De Klerk \& Duvenage, 1973, p. 318). Since school should be seen as an institution which has as its function to complement the parental home, it follows that education in school is likewise aimed at opening up the ethical function of the educand in particular. Teachers do not replace parents, but are complementary parents who teach and educate the child in the extension of the spirit and direction of the parental home.

"Forming, shaping, moulding" (the meaning core of the historic function which is the founding function of all education) and "ethical love", "managing" of the educand (Stoker, 1967, p. 251), "reliability" (Taljaard, 1976 , p. 106) are therefore the two matters very prominent in the educative event. The former suggests that all formative action qualifies as education (leading, agogy), and the latter that the educative event always takes place in the interest of the educand, the "object" of the leading/guidance event or the influencing event.

A single example will sufficu to explain this point of view: should some driver of a motor-car execute an illegal U-turn in a very busy street, a traffic officer may take action in the expected manner - stop the car and issue a ticket for the infringement. This action by the officer is unmistakeably an action characterized by authority, authority which is juridically qualified, and which can consequently not be taken for educative action. He acts towards the culprit as an officer in the service of the state or the city council who has to perform his job in the interest and according to the mandate of the state or city council. Should, however, this same traffic officer, after having issued the ticket, patiently and in the interest of the driver of the car explain to him that he has not only disrupted the traffic by making the turn, but has also endangered the lives and safety of other users of the street, he is in fact guiding, forming and influencing the driver of the car. This formative, influencing and guiding act is inspired by the ethic function - the act is performed in the interest of the person who is being led, and is therefore designated as "education".

I'rom this single example - and such examples can be multiplied - it is clear that education is a lifelong event or action which is terminated only by the death of the "educand" (who can even be an elderly person). Once this point of vicw has been accepted, one cannot any more regard education as an cuent that is terminated by tise attainment of "adulthood". Still, the use of the term "adulthood" may yet prove to be useful, and a probable alternative use ol it still has to le investigated. In order to do this meaningfully an 
investigation into the true universal goal of all education, and also into the various educational phases and their respective (common) "borders" (aims) has to be undertaken.

\section{The eventual goal of all education}

The argument in paragraph 2 (supra) followed a rather negative path: it was repeatedly indicated that operating with the term "adulthood" as general, universal aim of education causes many difficulties. It is a very vague term, very general and in fact meaningless if taken at face-value. At most it indicates a "borderline", an arbitrary "borderline" between childhood and adulthood, a "borderline" which can be manipulated at will according to the particular (religious) point of view held by an educator.

Since "adulthood" evidently can not be regarded as the universal aim or goal of all education wherever it takes place, what should then in fact be regarded as the actual goal of all education? A possible solution is suggested by Van der Walt and Dekker $(1978$, p. 74$)$ in their use of the expression: "complete 'adulthood' hereafter". Placing the eventual goal of education in the hereafter has its own particular shortcomings, for example that the goal then becomes "a pie in the sky when you die"; it becomes something which is not attainable here and now and consequently cannot inspire the educator (parent and teacher) to purposeful teaching. However, it also shows some advantages: it is a "fixed" goal ("fixed" not to be understood in absolute terms), it is unattainable (and this is something the Christian educator always takes into account), it allows for the specific characteristics of practical education, it is clear and unambiguous, it serves as a guiding line for all education, it is commodious and extensive, it is fairly elastic, flexible, adaptable and adjustable, it suggests the use of certain methods of education, and - above all - it supplies in the most deeply rooted needs of man (i.e. educand and educator).

Why does it supply in man's innermost needs? Because this aim of " 'adulthood' hereafter" can best be circurnscribed as the religious goal of all education.

Coetzee (1965) must receive full credit for the fact that he pointed out to teachers many years ago that every educator, whoever and wherever he may be, always has a religious aim which he aims to realize in his educational work with children (or other people, as will be later illustrated). The term "religion" means the "binding back" of the heart of man (educand or educator) to Its origin/Origin. In the case where the Origin is the true God of the Scriptures, we can refer to the true religion, and it may be expected that 
the educational work done by such an educator will be truly religiously inspired, that it will be aimed in the last instance at the honour and the glory of the true God who has revealed Himself to us in the Scriptures. All his educative work will, as a natural consequence of the fact that his heart is bound to God, be done in the interest of the educand entrusted to him and in the interest of the cosmos over which man was given the mandate to govern (Van der Walt, Dekker \& Van Wyk, 1978, p. 38 ff). On the contrary, if a false god, or idol, has "laid claim" to the heart (the core of man's personality), all his deeds - including the educative work done by him - will be falsely religiously aimed and inspired (ideologically, apostatically), aimed at the honour and the glory of the idol which has taken possession of his heart.

The view of religion expounded above has two implications: the first is that "adulthood" per se, taken at face value, cannot be regarded as the universal goal of all education, since religious service to the God/god who has taken possession of the educator's heart is to be regarded as the aim of all man's deeds - including his educative work. The second implication is that people entertain radically different views of "adulthood" precisely because of their religious orientation. I'or instance, the well-known theologian, Dr Dorothee Sölle, regards "adulthood" as the condition of being completely independent from God. Only children depend on Him for comfort and safety (Van Dijk, p. 45). In her opinion education is a process which renders a person "mature", i.e. independent of God; it is a process which liberates man and which is aimed at the "Umwertung aller Werte". It is, however, quite evident that her views of "adulthood" and of education are religiously inspired and determined. In contrast to Sölle's view of "adulthood" and the aim of education, Coetzee (1954, p. 221-2) maintains that true "adulthood" amounts to complete dependence on the true God of the Scriptures. "To know and to fear Him is the ultimate aim of our life and education; God (is) the origin, the principle as well as the destination of man", he asserts. According to his view, the "adult" person should fear the Lord, should seek truth, should evade all that is wrong and should seek peace.

It would be fair to infer from these contrasting points of view that they are motivated and inspired by the fact that the two persons in question entertain different religions: that the heart of one is the religious possession of a god which bears the name of "Revolution", whilst the heart of the other belongs to the true God of the Scriptures. 


\section{7. "Fixed border lines"?}

For the purposes of the present exposition we can divide the educational process (which can start pre-natally and which is terminated by the death of the educand) into four distinguishable phases, viz. the pedagogical, the neaniagogical ${ }^{1}$, the andragogical and the gerontagogical phases. In view of our concept of the universal goal of all education, wherever it takes place, we take it as a matter of course that each of these educational (agogical) phases has as its eventual, long distance aim the religious service of both educator and educand towards the god/God who has laid claim on his heart.

If we take "religious service to the origin" as the eventual goal of education, we still have to consider what may be regarded as the specific goal of the educative process in each of the four educational phases mentioned above. To state the problem in somewhat different terms: what are the "border lines" between the four educational phases, or: when can a person still be called a child, or when has he become an adolescent, or a "grownup" or an elderly person?

It is not the aim of the present exercise to enter into full detall concern. ing this problem. It will suffice to say that "adulthood" per se cannot be the aim of any one of these four stages, and that "religious service to the origin" should be regarded as the all-encompassing aim of all four stages. It is also suggested that the attainment of the power of formal-operational thinking be taken as the "border line"2) between the child and the adolescent and consequently between pedagogy and "neaniagogy". As for the "border line"

1) This term is "borrowed" from a colleague at the UCT, Mr G.K. Bauer, who discussed the possible use of it with the present author at the SAAAE conference in Stellenbosch in January 1979. It is derived from the Greek "neanias" (new, youth) and "agoo" (I lead).

2) The term "border line" should not be taken in absolute terms: the transition from one agogical phase to the following is gradual and often takes years to be completed. In some cases the transition does not even take place. Ashton (1975, p. 9) for instance mentions "an early arrest in cognitive development in traditional non-industrialized cultures", Dasen (1972, pp. 27, 30-31) mentions research which indicates that persons belonging to certain cultures never complete the concrete operational stage. In these cases the "border line" between pedagogy and neaniagogy becomes problematic. In the case of the white South African child we can, however, accept the attainment of formal thinking ability as a probable "borderline". Formal thinking ability is, however only one aspect of the whole profile of the adolescent, but it is incidentally an aspect which can be cxperimentally established and verified. 
between the adolescent and the "adult", between "neaniagogy" and andragogy, it is suggested that the attainment of Kohlberg's stage 5 of moral development be taken. Kohlberg $(1975$, p. 671$)$ points out that only about 10 percent of those persons who attain the formal operational stage ever reach stages 5 and 6 of moral development as distinguished by him. Only these people may be regarded as true "adults" - in the moral sense of the word. However, man is not merely a moral begin; in the final analysis he is a religious being. The question now rises: when can a person be regarded as an "adult" in the religious sense of the word? According to the exposition $6 f$ the "religious aim" of all education one is compelled to reply: Never, not in the present dispensation. What, apart from the attainment of Kohlberg's stage 5 of moral development, may then be regarded as a feature of the "andros" (man, "adult", "grown-up") by which he may be distinguished from the child and adolescent? We will turn to this question again presently, after having suggested a "border line" between the "grown-up" (andros, man) and the elderly person (gerontos), between andragogy and gerontagogy.

The only feasible "border line" between these two agogical phases which actually presents itself is the point of retirement. Life before retirement differs markedly from life after this point: there is a shift not only in emphasis but also in quality. Life after retirement is a period of consolidation and preparation for death which eventually will have to come. Also this "border line" is not to be understood in absolute terms: many retired people remain active for many years after retirement. The point is: the elderly person, too, can be guided, can be formed and influenced by some other person or persons - hence the term "gerontagogy". The question which will next have to be answered, is: what are the characteristic features of the leading, forming, influencing process (agogy) in the case of the "grown-up" (man) and the elderly person, in contrast to the leading, forming, influencing (agogic, educative) process in the case of the child and the adolescent (youth)? What features distinguish the "adult" and elderly person from the child and adolescent? May we seek the difference in the respective stages of moral development or not?

\section{A "new" conception of "adulthood"}

These last questions have brought us to the stage of the argument in which a "new" conception of "adulthood" may be considered. For this purpose let us for a brief moment return to our example of the traffic officer (paragraph 3). It was indicated that the officer in question acted in two dif- 
ferent ways in his relationship with the driver of the motor-car, and that each of these ways of acting was characterized by his having authority. In the first instance, when he issued the traffic ticket, his action was fraught with juridical authority, and in the second, when he reprimanded the culprit in the latter's own interest, it was fraught with educative, i.e. ethical, authority. It is common knowledge that freedom supposes authority (and vice versa), and that the exertion of authority is again aimed at the attainment of independence and responsibility (of the educand, in the educational context) cf. also Botha, 1973,p. 4). All these "things", freedom, authority, independence, responsibility, pertain to the moral or ethical function or capability of man (i.e. the educand) (cf. Coetzee, 1965, p. $104 \mathrm{ff}$ ).

Let us concentrate only on authority for the present: educative authority is, as illustrated by the example, always moral or ethical authority. Reconsidering the fashion in which authority is exerted in each of the four agogical phases in paragraph 7, one comes to the evident conclusion that the first two phases (the pedagogical and neaniagogical) differ qualitatively from the last two, especially as regards the wielding of authority by the educator (who is burdened with the task of leading, moulding, forming, influencing another person entrusted to his care). In the first two phases the educator not only possesses the authority to address himself to the educand, but also has the specific authority to take action against the educand if it is deemed necessary. This means that he may actually punish and chastise the educand if he judges that it will be in the interest of the latter.

In the last two agogic phases the nature of the authority which is exerted by the leader/influencer/moulder/educator (in the widest sense of the word) differs qualitatively from the first two: he still has the authority to address himself to the person who is being led (etc.), but he does not any more have the competence to take authoritative action when he decides that the other person is in need of it; the person who is being led (etc.) can not any more be punished or chastised if he rejects the influence, the act of guiding by the educator. For some or other reason the quality of the authority wielded in the last two agogic phases is different from that of the first two - and this reason is most probably the fact that the educand has become an "adult". Father, mother and/or teacher comes to tie realization at some point in the development of the child (a point which can actually be indicated with a certain amount of correctness) that he or she can no longer take authoritative action against the child; he or she realizes that the child, who has now become "mature", can only be addressed with authority.

What has happened to the educand (who has now become an "adult") in the meantime? Why can he be called an "adult"? What does "adulthood" in 
this context mean? The answers probably lie in the fact that the normative act-structure has become opened up (which suggests that he has become mature in thought, in the use of language and symbols, in the understanding of culture, in social relationship, in his consideration of values, in his appreciaton of beauty and harmony, in his ability to adhere to rules and maintain a regular life, his conscience has developed to maturity, and he has found security in life). Since education is specifically aimed at the moral or ethical ability of the child, it is this ability or function which especially should have developed to full maturity before one can refer to the educand as an "adult", as somebody belonging to the andragogic and eventually the gerontagogic phases of the total educative event. This also clarifies the fact that Kohlberg's stage 5 (and 6) of moral development is as it were "reserved" for the true adult - who belongs to a group of only 10 percent of those people who actually attain formal operational thinking ability.

Since we are considering the use of "adulthood" as a universal educational goal, we now have to conclude that

* education is a life-long process or event;

* "religious service to the origin" is the universal goal of all education:

* the educative process can be divided into four agogic phases;

* each of these phases has its own educative aims;

* "adulthood" can not be regarded as the universal goal of the whole educative process;

* "adulthood" may be regarded as the universal goal of the pedagogic and the "neaniagogic" phases;

* "adulthood" is a matter of complete maturity on the part of the educand, and especially of his moral and religious/pistic functions.

\section{The proof of the pudding...}

In order to test this "new" conception of "adulthood", let us turn to a particular educative situation, viz. a Christian educative situation: according to the baptismal vow the parent (and eventually the teacher) is not only competent but also compelled to both address himself to the educand and to take action against the educand if deemed necessary. The authority by which this is done is ethically qualified, which means that the parent's authority is exerted in the interest of the child. In the event of misconduct on the part of the educand in the educative situation (e.g. he decides to reject the guidance of the parent or teacher), the educator possesses the Godgiven authority to punish the child in order to help him to mend his ways. The criterion for cducative action (in this case punishment) is whether such 
action is being taken in the interest of the educand. If such action is not specifically aimed at the moulding, opening up or guidance of the educand, it makes non-sense in the educative situation and has to be avoided.

The parent/teacher guides and leads the child in the pedagogical and neaniagogical phases of the educative process with the avowed aim of realizing the goals of these two phases: to help the child across the "border line" in each case. As time passes the educator begins to realize that he can no longer take authoritative action against the educand, since the educand has become mature. After this point in time the educator still has the authority, the competence as well as the duty to guide the child in an educatively sensible manner, but now the educand has become sufficiently mature and independent to decide for himself - at his own expense or advantage - whether to accept or to reject the proferred guidance. The fifth commandment still remains operative: it does not matter to what extent the educand is morally mature; he still has to subject himself obediently to the good teachings and punishment of his parents and everybody else appointed above him, since it is the pleasure of God to govern us by their hand (H.C. A/A 104). The authority of the parent is never abolished or repealed and remains operative as long as the parent lives - but the quality of the exertion of authority changes at some point in time after which the child may decide for himself whether to accept or to reject his parent's guidance.

This "new" conception of adulthood coupled with the view that education is a life-long process also opens the following perspective: in the andragogic and gerontagogic phases of the total educative process a specific person (whom we shall call $\mathrm{X}$ ) can address himself to another person in order to guide the latter. This is possible on only one condition, namely that $X$ must avail himself of some or other competency which will render his address to the other person an address with authority (which does not mean that he also may claim the right to take authoritative a-tion against this other person should he decide to reject X's guidance). The authority referred to actually flows or proceeds out of some competency which $X$ has at his disposal in regard to the other person: it is possible that $\mathrm{X}$ is older than the other person, or that he has more knowledge (cf. the pastor who is guiding a terminal patient), or that he holds some office (pastor, reverend. deacon, clder). Only a single condition is established for this concem of $X$ with the ofther person in order to name his "meddling" with the ciller person colucation, namely that everything which is said and dome by $x$ sheuld be in the sole: interest of the other person with whom $\mathrm{X}$ comrerns himself. Comrorn which is inspired by any other motive can and in:ly $110 \mathrm{lw}$. laken lor education, for agogy. 


\section{Conclusion and summary}

Since "adulthood" can not be accepted as the goal of all educative work, wherever and by whom it is being done, an alternative had to be suggested. It was suggested that "religious service to the God/god who has taken pos. session of the educator's heart" be accepted instead. This "religious service" is to be taken as the universal goal of all education, all true education wherever it may be encountered. As a consequence it is also the universal goal of pedagogy, neaniagogy, andragogy and gerontagogy, since these are merely the four stages of the whole educative process.

Acceptance of "religious service to an origin" as the all-embracing goal of all educative work brought along some serious problems: if "adulthood" can not apply as the aim of only the pedagogic phase, what should then be accepted as the goal of pedagogy - and likewise of neaniagory, andragogy and gerontagogy? Without entering into great detail it was suggested that the transition to formal operational thinking ability be regarded as the aim of pedagogy, that attainment of Kohlberg's stage 5 of moral development be regarded as the aim of neaniagogy, that retirement be regarded as the "border line" between andragogy and gerontagogy.

These aims pose the following challenge to the educator (in the widest sense of the word): in the pedagogical phase he will have to guide the child to the attainment of formal operational thinking ability (along with the accompanying features of formal operational thinking ability); in the neaniagogical phase it is his task to guide the adolescent to the complete attainment of Kohlberg's stage 5 of moral development, i.e. to complete moral maturity of "adulthood"; in the andragogical phase to guide tite adult or grown-up to the point of retirement (which is such a great task that we can make no effort to circumscribe it here), and in the gerontagogical phase to guide the retired person during the consolidation and winding-up period of his life, the phase that is terminated only by death.

In the previous paragraph a "new" use of "adulthood" was indicated: an adult is a person who may (and should) still be guided by other people having some or other authority behind them, but the guider, the "leader" may not exert his authority by taking authoritative action any more. This action is reserved only for the pedagogical and neaniagogical phases.

All educative work has only one all-embracing goal, i.e. religious service. In the case of the Christian this all-embracing goal is interpreted as equipping the educand fully for every good work (cf. 2 Tim. 3:17) - and this applies for each of the agogical phases mentioned.

It becomes clear that the socialist, the pragmatist, the communist, the 
Maoist (and many more can be mentioned) will each have his own interpretation of the all-embracing religious goal and will organize its content accordingly.

\section{BIBLIOGRAPHY}

1. ASHTON, Patricia. 1975. Cross-cultural Piagetian research: an experimental perspective. Harvard Educational Review, 45(4):475-506.

2. BOTHA, M. Elaine. 1973. Gesag en vryheid. (Paper read at Conference on Youth Preparedness. PU for CHE. 5 October 1973.)

3. CLAASSEN, J.T. n.d. Die betekenis van die Skool as ontsluitingsmag na Christelike beskawingsmondigheid. Potchefstroom. (Unpublished M.Ed. dissertation - PU for CHE.)

4. COETZEE, J.C. 1965. Inleiding tot die algemene teoretiese opvoedkunde. Pretoria, Van Schaik.

5. DASEN, P.R. 1972. Cross-cultural Piagetian research: a summary. Journal of Crosscultural psychology. Vol. 3:29-33.

6. GUNTER, C.F.G. 1970. 'n Christelike georiënteerde opvoedingsfilosofie. Stellenbosch, Universiteitsuitgewers.

7. Heidelberg Catechism. 1947-version (Afrikaans).

8. KOHLBERG, L. 1975. The cognitive-developmental approach to moral education. Phi Delta Kappan, June 1975.

9. LANDMAN, W.A. \& GOUS, SJ. 1969. Inleiding tot die Fundamentele Pedagogiek. Johannesburg, APB.

10. LANDMAN, W.A., ROOS, S.G. \& LIEB ENBERG, C.R. 1971. Opvoedkunde en opvoedingsleer vir beginners. Stellenbosch, Universitaitsuitgewers.

11. SCHOEMAN, P.G. 1975. Grondslae en implikasies van 'n Christelike opvoedingsfilosofie. Bloemfontein, Sacum.

12. STOKER, H.G. 1967, Oorsprong en rigting. Part 1. Kaapstad, Tafelberg.

13. TRöSCH, Gisela. 1978. Ich diene den Gips Köpfen als Holzwolle. Duetsche Zeutung. Nr. 10:15. Den 3. März 1978.

14. TALJAARD, J.A.L. 1976. Polished lenses. Potchefstroom, Pro Rege-Pers.

15. VAN DER WALT, J.L. \& DEKKER, E.K. 1978. Inleiding in die Fundamentele Opvoedkunde. Part 2. Potchefstroom, Pro Rege-pers.

16. VAN DER WALT, J.L., DEKKER, E.I. \& VAN WYK, J.H, 1978. Inleiding in die Fundamentele Opvoedkunde. Part 1. Potchefstroom, Pro Rege-pers.

17. VAN DUJK, M.P. 1974. De uitdaging van het Neo-Marxisme. Amsterdam, Buijten \& Schipperheijn. 
18. VAN WYK, J.H. 1974. Kosmologie, opvoeding en opvoedkunde. (Unpublished lectures, PU for CHE).

19. VAN WYK, J.H., DE KLERK, WJ. \& DUVENAGE, B. 1973. Roeping en werklikheid. Potchefstroom, Herald. 